\title{
Experiment Research of a Certain Pb-Zn in Guangxi
} Huawei Yuan ${ }^{1,2, a}$, Quanjun Liu ${ }^{* 1,2, b}$,Yichao Zhang ${ }^{1,2, \mathrm{c}}$, Hui Zhang ${ }^{1,2, \mathrm{~d}}$

${ }^{1}$ Faculty of Land and Resource Engineering, Kunming University of Science and Technology, Kunming, China

${ }^{2}$ State Key Laboratory of Complex Nonferrous Metal Resources Clean Utilization, Yunnan, China

Kunming University of Science and Technology, Kunming, China

ayuanhw1991@sina.cn, ${ }^{\text {b } k m l i u q j @ s i n a . c o m ~}$

Keywords: oxygen sulfur mixed lead-zinc; combined depressants; selective flotation

\begin{abstract}
By summarizing and analyzing the results of the condition experiments and considering the process mineralogy, for the oxygen sulfur mixed lead-zinc in Guilin, Guangxi, it has been determined lead sulfide - zinc sulfide - lead oxide flotation processes.
\end{abstract}

\section{Introduction}

Oxygen sulfur mixed lead-zinc mineral is variety, various minerals are associated closely, and disseminated grain size is fine, these characteristics always make the process more difficult. The high cost and a wide using of various of pharmaceutical also restrict the utilization. China's lead and zinc ore resources is abundant, the ore type is complex, useful associated elements are numerous thus can be possessed of comprehensive utilization, but also makes it difficult to smelt.

The test ore was taken from a certain oxygen sulfur mixed lead-zinc ore in Guilin, Guangxi. Using the process of sulfide ore flotation firstly and oxide ore flotation followed, lead election firstly and zinc election followed. There are explored researches for the grinding fineness and pharmaceutical research institution, which nicely realized effective separation of lead and zinc, and gained a good indicators.

\section{The crude ore properties}

We have researched on the run-of-mine ore. The results of multi-element are shown in Table 1.

Table 1 multi-element analysis results of ore/\%

\begin{tabular}{cccccccc}
\hline Element & $\mathrm{Pb}$ & $\mathrm{Zn}$ & $\mathrm{C}$ & $\mathrm{Ti}$ & $\mathrm{Fe}$ & $\mathrm{Ag}^{1)} / 10^{-6}$ & $\mathrm{Au}^{1)} / 10^{-6}$ \\
Content & 3.62 & 8.20 & 6.75 & 0.37 & 8.69 & 34.13 & $<0.05$ \\
\hline Element & $\mathrm{S}$ & $\mathrm{P}_{2} \mathrm{O}_{5}$ & $\mathrm{Mn}$ & $\mathrm{CaO}$ & $\mathrm{MgO}$ & $\mathrm{SiO}_{2}$ & $\mathrm{Al}_{2} \mathrm{O}_{3}$ \\
Content & 7.63 & 0.31 & 0.21 & 14.3 & 8.5 & 38.6 & 5.23 \\
\hline
\end{tabular}

1)unit is $g / t$.

It can be seen from the results of the analysis that recyclable elementals are lead, zinc, silver in the mine. Grade of lead is $3.62 \%$, zinc is $8.20 \%$, content of other elements is low, thus it's unnecessary to recycle. The main vein minerals are carbonate and silicate minerals.

\section{Process design}

Taking on grinding fineness test before flotating, thus useful minerals in the ore can be fully dissociated to reach the suitable size for flotating, receive higher metal recoveries and concentrate grade. Therefore, we must reach a certain grinding fineness, in order to achieve an effective separation of minerals. Grinding fineness trials are conducted under the stationary flotation process 
and initial conditions, and determine the best grinding fineness by controlling the grinding time. Grinding fineness test processes and pharmaceutical system are shown in Figure 1, the test results are shown in Figure 2.

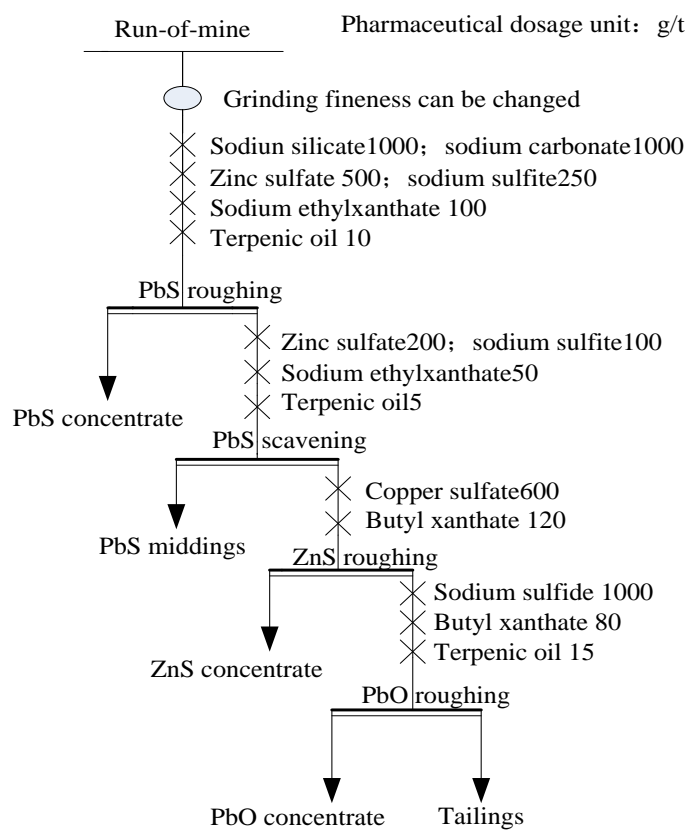

Fig.1 Grinding fineness test flow chart and reagent system

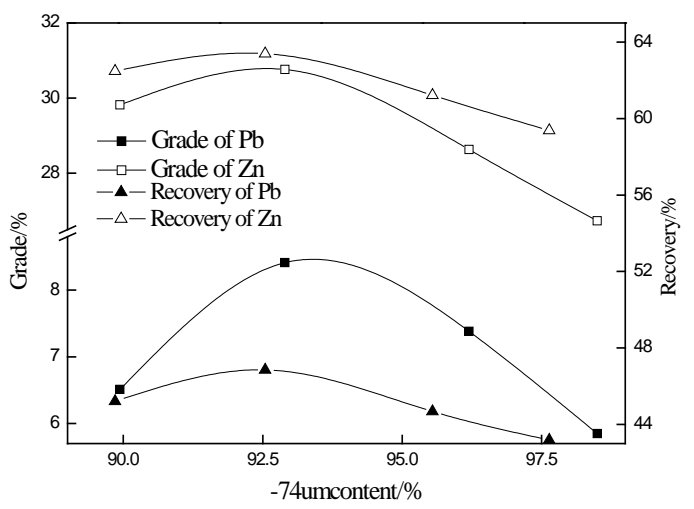

Fig.2 Grinding fineness test results

It can be seen from Figure 2, the impact of the flotation grinding fineness to index is significant, the concentrate grade decline and the recovery increases firstly and then decreases with the increase of the grinding fineness. The main reason is that ground ore is too thin to be separated from froth, thus will influence the concentrate grade. Both recovery of Lead and zinc increase firstly then decrease with the increase of grinding fineness, it illustrates that it's helpful to improve recovery if increases grinding fineness within certain limits, but it's not suitable to grind excessively. This is due to the increase in the extent appropriate grinding fineness is beneficial for minerals monomer dissociation, helpful to increase flotation recoveries. However, it will cause over crushing, and resulting in decreased recovery. It can be seen from Figure 2, if under 200 mesh accounted for 94\%, then grinds further it will cause adversely flotation index, so it can be confirm initially under 200 mesh content $94 \%$ as lead roughing grinding fineness.

\section{Recommended process}

According to the nature of the ore, use zinc sulfate and sodium sulfite as zinc sulfide's inhibitors to sort lead sulfide concentrate, then use copper sulfate as activator to sort zinc sulfide concentrate, use sodium sulfite as activator to sort lead oxide concentrate, to ensure that the grinding fineness under 
200 mesh constitute 94\%, the closed circuit is shown in Figure 3 below, the test results are shown in Table 2.

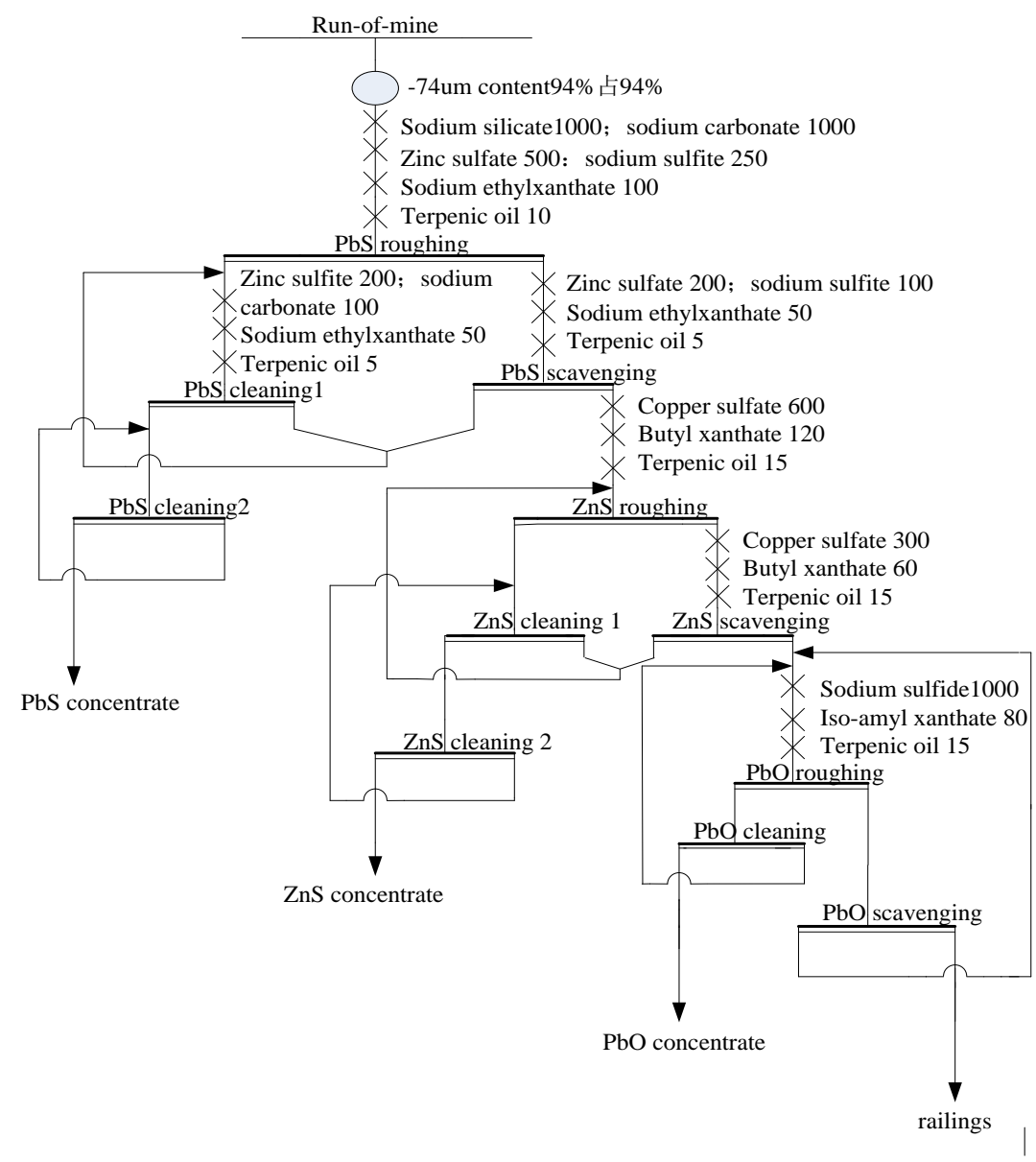

Fig.3 Flow sheet of closed circuit test

Table 2 Results of closed circuit test

\begin{tabular}{cccccccc}
\hline \multirow{2}{*}{$\begin{array}{c}\text { Product } \\
\text { name }\end{array}$} & \multirow{2}{*}{ Production/\% } & \multicolumn{3}{c}{ Grade/\% } & \multicolumn{3}{c}{ Recovery/\% } \\
\cline { 3 - 8 } & & $\mathrm{Pb}$ & $\mathrm{Zn}$ & $\mathrm{Ag} /[\mathrm{g} / \mathrm{t}]$ & $\mathrm{Pb}$ & $\mathrm{Zn}$ & $\mathrm{Ag}$ \\
\hline $\mathrm{PbS}$ & 6.85 & 13.20 & 3.12 & 123.93 & 24.30 & 2.60 & 24.80 \\
$\mathrm{ZnS}$ & 12.35 & 1.80 & 46.80 & 80.19 & 5.97 & 70.27 & 28.94 \\
$\mathrm{Pb0}$ & 9.70 & 15.10 & 2.34 & 10.46 & 39.36 & 2.76 & 2.96 \\
Railings & 71.10 & 1.59 & 2.82 & 20.84 & 30.38 & 24.38 & 43.29 \\
Run-of-mine & 100.00 & 3.72 & 8.23 & 34.22 & 100.00 & 100.00 & 100.00 \\
\hline
\end{tabular}

It can be seen from the data in Table 2, the grade of lead in lead sulfide concentrate get from the closed process is $13.20 \%$, the recovery is $24.30 \%$. the grade of zinc in zinc sulfide concentrate is $46.80 \%$, and the recovery is $70.27 \%$, the grade of lead in lead oxide concentrate is $15.10 \%$, the recovery is $39.36 \%$. Although the content of lead in lead sulfide concentrate is very low, but silver has been associated, the grade of silver in lead sulfide concentrate is $123.93 \mathrm{~g} / \mathrm{t}$, the recovery is $24.80 \%$, so it can be considered as silver concentrate.

\section{Conclusions}

The test ore samples was taken from a certain oxygen mixing sulfur mine in Guilin, according to the mineralogy studies, the grade of lead in rude ore is $3.62 \%$, the grade of zinc is $8.20 \%$, associated metallic silver grade is $34.13 \mathrm{~g} / \mathrm{t}$, the ore was highly oxidized, which belonging to the low-grade and highly oxidized ore. 
For the nature of the ore characteristics, developed a lead sulfide - zinc sulfide - lead oxide flotation process, gained the lead grade 13.2\%, 23.06\% recovery of lead sulfide concentrate, zinc grade of $46.80 \%, 70.20 \%$ recovery of zinc sulfide fine ore, lead grade $15.10 \%$, $39.67 \%$ recovery of lead oxide concentrate. Lead in lead sulfide concentrate grade is not high, but the associated silver get a better recovery, concentrate grade of $123.93 \%$ silver recovery of $24.80 \%$.

\section{References}

[1] Lin M.Q,Wei Z.W,Mo W,Chen Q,F.Experimental Research on Lead-Zinc Separation of Refractory Lead-zinc Ore from Guangxi.Metal Mine2007;10:72.

[2] Liu Y,C.Experimental Research on Gravity-Flotation Flowsheet for Treating Sulfide-Oxidized Pb-Zn Mixed Ores.Sichuan Nonferrous Metals2002;2:41.

[3] Qiu T.S,Zhao G.F,Zhu D.M,Yang Y,Zhang B.H.Benefiation Tests of a Refractory Lead-Zinc-Sliver Sulfide in Sichuan Province.Metal Mine2012:12:64-65.

[4] Wang Y.J,Wen S.M,Liu J,Lv M,Y.Deng J,S.Introduction of Zinc Deperessants and Activators and their Function Mechanism in Lead-Zinc Separation.Mining\&Metallurgy2012;4: 22-23. 